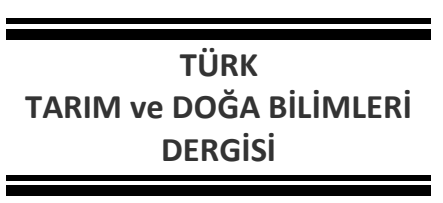

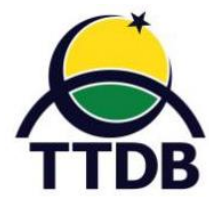

www.dergipark.gov.tr/turkjans

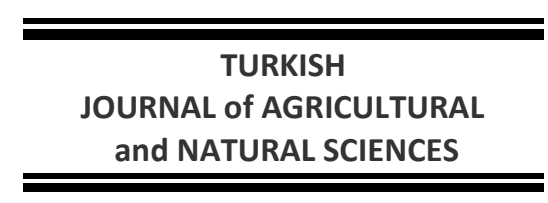

Araştırma Makalesi

\title{
Elazığ Koşullarında Bazı Mürdümük (Lathyrus sativus L.) Genotiplerinin Tohum Verimi ve Tohum Verimini Etkileyen Bazı Özelliklerinin Belirlenmesi
}

\author{
Selim ÖZDEMiR ${ }^{1 *}$,Kağan KÖKTEN ${ }^{2}$, Mahmut KAPLAN $^{3}$, Rıdvan UÇAR ${ }^{2}$ \\ ${ }^{1}$ Bingöl Üniversitesi, Teknik Bilimler MYO, Bitkisel ve Hayvansal Üretim Bölümü, Tarla Bitkileri Programı, Bingöl \\ ${ }^{2}$ Bingöl Üniversitesi, Ziraat Fakültesi, Tarla Bitkileri Bölümü, Bingöl \\ ${ }^{3}$ Erciyes Üniversitesi, Ziraat Fakültesi, Tarla Bitkileri Bölümü, Kayseri \\ *Sorumlu yazar: ozdemir2312@gmail.com
}

Geliş Tarihi: 12.02.2020 Düzeltme Geliş Tarihi: 10.03.2020 Kabul Tarihi: 13.03.2020

\begin{abstract}
Özet
Araştırma, Elazığ ekolojik koşullarında bazı mürdümük genotiplerinin tohum verimi ve verim üzerinde etkili bazı öğelerin incelenmesi amacıyla, 2014-2015 yıllarında yazlık ekim yapılarak yürütülmüştür. Araştırmada, 31 adet mürdümük genotipi bitki materyali olarak kullanılmıştır. Araştırma tesadüf blokları deneme desenine göre üç tekrarlamalı olarak kurulmuştur. Araştırmada; biyolojik verim, tane verimi, dolu bakla sayısı, boş bakla sayısı, bakla boyu, bakla genişliği, bitkide tane sayısı, bitkide tane ağırlığı, gibi verime etki eden özellikler incelenmiştir. Araştırmanın yürütüldüğü her iki yılda da; biyolojik verim hariç incelenen diğer tüm parametreler bakımından genotipler arasında istatistiki anlamda önemli farklııklar belirlenmiştir. Araştırma sonucuna göre; genotiplerin biyolojik verimi $188.72-271.18 \mathrm{~kg} / \mathrm{da}$, tane verimi $75.10-117.72 \mathrm{~kg} / \mathrm{da}$, dolu bakla sayıs $7.16-16.15$ adet, boş bakla sayısı 0.06-1 adet, bakla boyu $2.78-3.45 \mathrm{~cm}$, bakla genişliği $0.83-1.23 \mathrm{~cm}$, bitkide tane sayısı 16.73-45.08 adet ve bitkide tane ağırlığı 2.03-4.23 g arasında değişim gösterdiği saptanmıştır. Araştırma sonuçlarına göre, Elazığ ili iklim ve toprak koşullarında tohum üretimi amacıyla "Hat-17" mürdümük genotipinin diğer genotiplere göre verim açııından daha üstün olduğu tespit edilmiştir. Söz konusu genotipinin ıslah materyali olarak diğer çalışmalarda da kullanııması önerilebilir.
\end{abstract}

Anahtar Kelimeler: Mürdümük, Lathyrus sativus L, tohum verimi, verim özellikleri

\section{Determination of Some Characteristics that affect Seed Yield and Seed Yield of Some Grasspea (Lathyrus sativus L.) Genotypes in Elazig Conditions}

\begin{abstract}
The research was carried out in 2014-2015 in order to determination of seed yield and features of some grasspea genotypes under the ecological conditions of Elazig. In the research; 31 different grasspea genotypes were used as plant material. The research was founded as a randomized complete block design with three replications. In the study; biological yield, seed yield, number of full pods, number of empty pods, pod length, pod width, seed number in the plant, seed weight in the plant, properties affecting the yield were investigated. In both years of the research; statistically significant differences were determined between the genotypes in terms of all other parameters examined except for biological yield.According to the research result; biological yield of genotypes $188.72-271.18 \mathrm{~kg} / \mathrm{da}$, seed yield $75.10-117.72 \mathrm{~kg} / \mathrm{da}$, number of full pods in the plant 7.16 16.15 , number of empty pods $0.06-1$, pod length $2.78-3.45 \mathrm{~cm}$, pod width $0.83-1.23 \mathrm{~cm}$, the number of grain in the plant 16.73-45.08 and grain weight in the plant varies between 2.03-4.23 g. According to the results of the research, it was determined that the "Hat-17" grasspea genotype was superior in yield relationship compared to other genotypes. The article of the genotype in question may be recommended in other studies as a breeding material.
\end{abstract}




\section{Giriş}

Baklagiller familyasına giren bitkilerin protein oranı yüksek olması, içeriklerinde vitamin ve mineralleri barındırmaları ve tarımı yapılan alanları organik madde bakımından zenginleştirmeleri gibi nedenlerden dolayı büyük öneme sahip bitkilerdir. Baklagiller familyasında giren birçok tek ve çok yıllık yem bitkisi bulunmakta olup bunlardan biri de mürdümüktür. Dünya genelinde en fazla kültürü yapılan Lathyrus türü L. sativus'tur. Mürdümük bitkisi, yıllık ortalama yağış miktarının 250 mm'e kadar azaldığı, bu özelliğinden dolayı da kuraklığa dayanıklı kültür bitkilerinin ilk sıralarında yer almaktadır (Tekele-Haimanot ve ark., 1990).

Mürdümük bitki türleri ülkemizin hemen hemen her bölgesinde doğal olarak yetişebilmektedir. Özellikle doğal mera alanlarında yapılan vejetasyon etütlerinde de yaygın mürdümük (Lathyrus sativus) bitkisine rastlanıldığı birçok araştırıcı tarafından rapor edilmiştir (Seydoşoğlu, 2018; Seydoşoğlu ve Kökten, 2019; Seydoşoğlu ve ark 2019). Genetik varyasyonu, kurak alanlardaki adaptasyon yeteneği ve diğer baklagil yem bitkilerinden daha kısa yetişme süresine sahip olmasından dolayı son yıllarda büyük ilgi görmüştür (Bucak ve Baysal, 2001). Lathyrus türleri dünya genelinde yeşil ve kuru ot veya tane yemi olarak hayvan beslenmesinde, yeşil gübre bitkisi olarak toprak yapısının iyileştirilmesinde ve yemeklik tane baklagil veya sebze olarak insanların beslenmesi için yetiştirilmektedir. Bunlara ek olarak, bu türler bazı zamanlarda hayvan otlatılarak yararlanılmakta, otlatmaya ara verildikten sonra tekrar büyüyen bitkiler tohum için yetiştirilmektedir (Kumar, 1997).

$\mathrm{Bu}$ araştırma, farklı mürdümük genotiplerinin tohum verimi ve verime etkili bazı öğelerin incelenerek Elazığ ve benzer ekolojilere uygun genotip veya genotiplerin belirlenmesi amacıyla yapılmıştır.

\section{Materyal ve Yöntem}

Bu çalışma, 2014-2015 yıllarında Elazığ ili, Merkez ilçesi, Çöteli Köyü'nde bulunan bir çiftçi tarlasında yazlık ekim yapılarak yürütülmüştür. Araştırmada çeşit, hat ve popülasyonlardan oluşan toplam 31 [452, 481, 504, 508, 520, 522, 528, 532, 553, 563, Hat-1, Hat-6, Hat-12, Hat-15, Hat-17, Hat18, Hat-19, Karadağ, Elazığ Popülasyon, Mardin Popülasyon, Adıyaman, Gürbüz, ifls 491, Ela, Colaratus, Albus, Leucotetragonus, Biflorus, İptaş, Azureus, Eren] adet mürdümük genotipi materyal olarak kullanılmıştır.

Çalışmanın yürütüldüğü Elazığ ili iklim verileri Elazığ Meteoroloji 13. Bölge Müdürlüğünden alınmış ve bu verilere bakıldığında; uzun yıllar aylık ortalama sıcaklık $13.01{ }^{\circ} \mathrm{C}$, toplam yağış miktarı $408.7 \mathrm{~mm}$ ve ortalama nispi nem değeri ise $\% 54$ olduğu görülmektedir. Çalışmanın yapıldığı 2014 yılında (12 ay) ortalama sıcaklık $15.1{ }^{\circ} \mathrm{C}$, toplam yağış $398.1 \mathrm{~mm}$ ve ortalama nispi nem \%51.1 iken, 2015(12 ay) yılında ise ortalama sıcaklık $14.1{ }^{\circ} \mathrm{C}$, toplam yağış $499.7 \mathrm{~mm}$ ve ortalama nispi nem \%54 olarak ölçülmüştür (Anonim, 2016).

Çalışmanın yapıldığı araziden $30 \mathrm{~cm}$ derinlikten alınan toprak numuneleri Bingöl Üniversitesi Toprak ve Bitki Analiz Laboratuvarında analiz edilmiştir. Analiz sonuçlarına göre; toprak bünyesi tınlı, tuzluluk sorununun olmadığı ve toprak $\mathrm{pH}^{\prime}$ sının ise hafif alkali olduğu görülmüştür. Organik madde içeriği çok az düzeyde olup, kireç ve fosfor içeriğinin orta düzeyde, potasyum içeriğinin ise yetersiz olduğu görülmüştür (Aydeniz ve Brohi, 1991). Tarlada kurulan Deneme, tesadüf blokları deneme desenine göre üç tekerrürlü olarak kurulmuştur.

Ekim, 2014 yılı 22 Mart tarihinde 2015 yılı 5 Nisan tarihinde, parsel uzunluğu $5 \mathrm{~m}$, sıra arası $30 \mathrm{~cm}$ olan parsellere 4 sıra halinde yapılmıştır. Ekimde her sıraya 100 adet tohum atılmıştır. Denemeye ekimden hemen önce dekara saf madde üzerinden $3,6 \mathrm{~kg}$ saf azot $(\mathrm{N})$ ve 9,2 kg saf fosfor $\left(\mathrm{P}_{2} \mathrm{O}_{5}\right.$ ) olacak şekilde DAP gübresi verilmiştir. Ekimden sonra, deneme parsellerindeki bitkilerin çıkışını sağlamak için yağmurlama sulama yapılmıştır. Parsellerdeki yabancı otlar yetişme döneminde çapa ile kontrol altına alınmıştır. Ekilen parsellerde özellikler her parseldeki bitkilerin altındaki 3-4 baklanın tümüyle sarardığı ve tanelerin sertleştiği dönemde her hattan rastgele seçilen 10 bitkide incelenmiştir. Hasattan sonra bitkiler torbalar içerisinde bekletilerek danelerin yeteri kadar sertleşmesi için bekletildikten sonra, tartım yapılmış, elde edilen değer dekara çevrilerek biyolojik verim elde edilmiştir. Biyolojik verimleri alındıktan sonra bitkiler harmanlanarak elde edilen tohumlar tartılmış ve dekara tane verimi olarak hesaplanmıştır. Bitkiler 2014 yılı 2 Temmuz tarihinde 2015 yılı 19 Temmuz tarihinde hasat edilmiş, her parselde 2. ve 3. sıralardan tesadüfî olarak alınan 10 bitkide meyveler sayılmış içerisinde tohum olanlar dolu bakla sayısı olarak kaydedilmiş, içerisinde tohum bulunmayan meyve sayıları boş meyve sayısı olarak hesaplanmıştır. Meyve sayımı yapılan 10 bitkide dolu meyveler içinden rasgele seçilen 10 baklanın boyu ve genişliği kumpasla ölçülmüş ve ortalama değer bakla boyu, meyve genişliğinin ortalaması da bakla genişliği olarak hesaplanmıştır. 10 adet bitkiden elde edilen tohumlar sayılıp ortalaması alınarak bitkide tane sayısı olarak kaydedilmiş ve bu tohumlar 0.01 grama duyarlı terazide tartılıp ortalaması alınarak bitkide tane ağırlığı bulunmuştur.

Araştırmadan elde ettiğimiz veriler, SAS istatistik programı kullanılarak tesadüf blokları deneme desenine analiz edilmiş ve ortalamalar arası farklılıklar DUNCAN yöntemiyle karşılaştırılmıştır (SAS Inst.-1999). 
Tablo 1. Biyolojik Verim ve Tane Verimine ilişkin ortalama değerler ve oluşan gruplar

\begin{tabular}{|c|c|c|c|c|c|c|}
\hline \multirow{2}{*}{ Genotipler } & \multicolumn{3}{|c|}{ Biyolojik Verim (kg/da) } & \multicolumn{3}{|c|}{ Tane Verimi (kg/da) } \\
\hline & 2014 & 2015 & Ortalama & 2014 & 2015 & Ortalama \\
\hline 508 & 189.13 a-d & 214.80 a-d & $201.97 \mathrm{bcd}$ & $70.27 c-1$ & 84.70 a-I & $77.48 \mathrm{de}$ \\
\hline 520 & 191.97 a-d & 198.57 a-d & $195.27 \mathrm{~cd}$ & ו-ו & 82.27 a-I & $79.48 \mathrm{de}$ \\
\hline 563 & 249.47 a-d & 251.13 a-d & $250.30 \mathrm{a}-\mathrm{d}$ & 99.43 a-ו & 104.53 a-ı & 101.98 a-e \\
\hline 531 & 180.83 a-d & 222.93 a-d & $201.88 \mathrm{bcd}$ & $68.53 c-1$ & I- & $79.97 \mathrm{de}$ \\
\hline 528 & 177.43 a-d & $200.00 a-d$ & $188.72 \mathrm{~d}$ & ו ו- 65.87 d & ו- 84.33 a- & $75.10 \mathrm{e}$ \\
\hline 522 & 204.27 a-d & 229.67 a-d & $216.97 \mathrm{a}-\mathrm{d}$ & 73.13 c-I & 100.83 a-ı & 86.98 a-e \\
\hline 504 & $156.70 \mathrm{~cd}$ & 262.97 a-d & $209.83 a-d$ & $56.77 \mathrm{ghı}$ & 136.47 a-e & 96.62 a-e \\
\hline Karadağ & $165.30 \mathrm{a}-\mathrm{d}$ & $322.23 a b$ & $243.77 \mathrm{a}-\mathrm{d}$ & $66.83 \mathrm{c}-1$ & $137.53 a-d$ & 102.18 a-e \\
\hline Elazığ Popülasyon & 201.43 a-d & $330.37 \mathrm{a}$ & $265.90 \mathrm{ab}$ & 80.60 a-1 & $149.77 \mathrm{a}$ & $115.18 \mathrm{ab}$ \\
\hline Mardin Popülasyon & $146.33 d$ & $311.87 \mathrm{abc}$ & 229.10 a-d & $59.90 \mathrm{f}-\mathrm{I}$ & $140.67 \mathrm{abc}$ & 100.28 a-e \\
\hline Adıyaman & 222.77 a-d & $253.53 a-d$ & 238.15 a-d & 85.97 a- & 106.93 a-ı & 96.45 a-e \\
\hline Gürbüz-2001 & 213.57 a-d & 274.83 a-d & $244.20 \mathrm{a}-\mathrm{d}$ & 84.73 a-1 & 121.00 a-h & 102.87 a-e \\
\hline ifls-491 & 248.70 a-d & $254.83 a-d$ & $251.77 \mathrm{a}-\mathrm{d}$ & 94.23 a-I & 105.90 a- & 100.07 a-e \\
\hline Ela & $213.43 a-d$ & 282.23 a-d & $247.83 \mathrm{a}-\mathrm{d}$ & 78.73 a-ı & 117.97 a-ı & 98.35 a-e \\
\hline Hat-1 & 180.10 a-d & $278.03 \mathrm{a}-\mathrm{d}$ & 229.07 a-d & I- ו $64.10 \mathrm{~d}$ & $124.77 a-h$ & 94.43 a-e \\
\hline Hat-6 & 263.07 a-d & 270.90 a-d & $266.98 a b$ & 100.40 a-I & 122.07 a-h & $111.23 \mathrm{abc}$ \\
\hline Hat-12 & 234.03 a-d & 291.43a-d & $262.73 a b c$ & 84.97 a-ו & 131.80 a-f & $108.38 \mathrm{a}-\mathrm{d}$ \\
\hline Hat-17 & 278.90 a-d & 231.87 a-d & $255.38 \mathrm{a}-\mathrm{d}$ & 105.37 a-I & $129.57 \mathrm{a}-\mathrm{g}$ & $117.47 \mathrm{a}$ \\
\hline Hat-19 & $259.63 \mathrm{a}-\mathrm{d}$ & $275.57 \mathrm{a}-\mathrm{d}$ & $267.60 a b$ & ו- 100.63 a- & 115.80 a-ı & $108.22 \mathrm{a}-\mathrm{d}$ \\
\hline Hat-15 & 263.07 a-d & 279.30 a-d & $271.18 a$ & 100.53 a-I & 115.57 a-ו & $108.05 \mathrm{a}-\mathrm{d}$ \\
\hline Hat-18 & $231.10 \mathrm{a}-\mathrm{d}$ & $274.83 a-d$ & 252.97 a-d & ו-a 86.70 & 116.23 a-ו & 101.47 a-e \\
\hline Coloratus & 203.07 a-d & 281.47 a-d & 242.27 a-d & ו- ו- 62.60 & 104.07 a-ו & $83.33 \mathrm{cde}$ \\
\hline Albus & 192.40 a-d & 288.20 a-d & $240.30 \mathrm{a}-\mathrm{d}$ & 61.07 f- & 110.83 a-ו & $85.95 \mathrm{~b}-\mathrm{e}$ \\
\hline 452 & $213.73 a-d$ & 294.10 a-d & $253.92 \mathrm{a}-\mathrm{d}$ & I ו- 69.97 & 118.47 a-ו & 94.22 a-e \\
\hline Leucotetragonus & $164.20 \mathrm{bcd}$ & $314.10 a b c$ & $239.15 \mathrm{a}-\mathrm{d}$ & 44.53 I & $122.50 a-h$ & $83.52 \mathrm{cde}$ \\
\hline Biflorus & $169.13 \mathrm{a}-\mathrm{d}$ & $292.60 \mathrm{a}-\mathrm{d}$ & 230.87 a-d & $52.40 \mathrm{hl}$ & 118.37 a-I & $85.38 \mathrm{~b}-\mathrm{e}$ \\
\hline İptaş & 226.47 a-d & 297.83 a-d & $262.15 a b c$ & 71.67 c-I & 124.73 a-h & 98.20 a-e \\
\hline Azureus & 196.83 a-d & 287.40 a-d & $242.12 \mathrm{a}-\mathrm{d}$ & $58.50 \mathrm{f}-\mathrm{I}$ & 115.67 a-ı & 87.08 a-e \\
\hline 481 & 234.67 a-d & 281.50 a-d & $258.09 a b c$ & 75.37 b- b & 130.17 a-g & 102.77 a-e \\
\hline Eren & 178.03 a-d & 297.07 a-d & $237.55 a-d$ & $62.10 \mathrm{f}-\mathrm{I}$ & 130.33 a-g & 96.22 a-e \\
\hline 553 & 209.77 a-d & 248.20 a-d & 228.98 a-d & $74.47 \mathrm{~b}-\mathrm{I}$ & $147.90 \mathrm{ab}$ & $111.18 \mathrm{abc}$ \\
\hline Ortalama & $208.37 \mathrm{~b}$ & $270.79 \mathrm{a}$ & 239.58 & $75.39 b$ & $117.52 \mathrm{a}$ & 96.45 \\
\hline
\end{tabular}

*Aynı harfle gösterilen ortalamalar $\mathrm{P} \leq 0.05$ hata sınırları içerisinde SAS istatistik analizine göre birbirinden istatistiki olarak farksızdır.

\section{Bulgular ve Tartışma}

Araştırmada kullanılan genotiplerin biyolojik verimleri yıllar arasında $\% 1$ düzeyinde, genotip $\mathrm{x}$ yıl interaksiyonu açısından \%5 düzeyinde önemli iken; genotipler arasındaki farklılığın biyolojik verime etkisi ise istatistiksel olarak önemsiz kaydedilmiştir. 20142015 yılı ortalama değerler dikkate alındığında; Tablo 1 de görüldüğü üzere en yüksek biyolojik verim
271.18 kg/da ile Hat-15 genotipinden elde edilirken, bunu istatistiki olarak aynı grupta yer alan ve 508 , 520,531 ve 528 nolu genotiplerin dışındaki diğer tüm genotipler izlemiştir. En düşük biyolojik verim ise $188.72 \mathrm{~kg} / \mathrm{da}$ ile 528 nolu genotipte saptanmıştır. Biyolojik verim değerleri 2014 yılında genotiplerin ortalaması 208.37 kg/da iken, 2015 yılında 270.79 $\mathrm{kg} /$ da olmuştur. 
Tablo 2. Dolu bakla sayısı, boş bakla sayısı ve bakla boyuna ilişkin ortalama değerler ve oluşan gruplar

\begin{tabular}{|c|c|c|c|c|c|c|c|c|c|}
\hline \multirow{2}{*}{ Genotipler } & \multicolumn{3}{|c|}{ Dolu Bakla Sayısı (adet/bitki) } & \multicolumn{3}{|c|}{$\begin{array}{l}\text { Boş Bakla Sayısı } \\
\text { (adet/bitki) }\end{array}$} & \multicolumn{3}{|c|}{ Bakla Boyu (cm) } \\
\hline & 2014 & 2015 & Ortalama & 2014 & 2015 & Ortalama & 2014 & 2015 & Ortalama \\
\hline 508 & 12.45 & 16.43 & $14.44 \mathrm{ab}$ & 0.66 & 0.65 & 0.66 a-d & 3.01 & 3.01 & $3.01 \mathrm{~d}-\mathrm{j}$ \\
\hline 520 & 11.23 & 14.22 & 12.73 a-e & 0.33 & 0.53 & $0.43 \mathrm{~b}-\mathrm{e}$ & 3.15 & 3.04 & 3.10 c-I \\
\hline 563 & 9.54 & 12.99 & $11.27 \mathrm{~b}-\mathrm{g}$ & 0.68 & 0.55 & 0.62 a-e & 3.10 & 3.07 & 3.09 c-j \\
\hline 531 & 9.35 & 10.12 & $9.73 \mathrm{~b}-\mathrm{g}$ & 0.43 & 0.53 & 0.48 a-e & 3.14 & 3.17 & $3.16 \mathrm{~b}-\mathrm{g}$ \\
\hline 528 & 13.01 & 14.86 & $13.94 \mathrm{abc}$ & 0.77 & 0.55 & $0.66 \mathrm{a}-\mathrm{d}$ & 3.20 & 3.18 & 3.19 a-f \\
\hline 522 & 11.33 & 12.09 & $11.71 \mathrm{a}-\mathrm{g}$ & 0.44 & 0.22 & $0.33 \mathrm{~b}-\mathrm{e}$ & 2.91 & 2.88 & $2.90 \mathrm{f}-\mathrm{j}$ \\
\hline 504 & 12.44 & 14.17 & $13.31 \mathrm{abc}$ & 1.00 & 1.00 & $1.00 \mathrm{a}$ & 3.11 & 3.13 & $3.12 b-h$ \\
\hline Karadağ & 8.88 & 12.22 & $10.55 \mathrm{~b}-\mathrm{g}$ & 0.44 & 0.44 & 0.44 b-e & 3.17 & 3.22 & 3.19 a-f \\
\hline $\begin{array}{c}\text { Elazığ } \\
\text { Popülasyon }\end{array}$ & 12.11 & 13.97 & $13.04 \mathrm{a}-\mathrm{d}$ & 0.33 & 0.42 & $0.38 \mathrm{~b}-\mathrm{e}$ & 2.95 & 3.10 & $3.03 \mathrm{~d}-\mathrm{j}$ \\
\hline $\begin{array}{c}\text { Mardin } \\
\text { Popülasyon }\end{array}$ & 6.89 & 11.81 & $9.35 \mathrm{c}-\mathrm{g}$ & 0.00 & 0.20 & $0.10 \mathrm{de}$ & 2.83 & 3.05 & 2.94 e-j \\
\hline Adıyaman & 8.23 & 13.12 & 10.68 b-g & 0.22 & 0.33 & $0.28 \mathrm{~b}-\mathrm{e}$ & 2.89 & 3.05 & $2.97 d-j$ \\
\hline Gürbüz-2001 & 9.45 & 10.96 & $10.21 \mathrm{~b}-\mathrm{g}$ & 0.22 & 0.33 & $0.28 \mathrm{~b}-\mathrm{e}$ & 2.96 & 2.98 & $2.97 d-j$ \\
\hline Ifls-491 & 7.33 & 8.00 & $7.67 \mathrm{fg}$ & 0.33 & 0.32 & $0.33 \mathrm{~b}-\mathrm{e}$ & 3.06 & 2.97 & $3.02 \mathrm{~d}-\mathrm{j}$ \\
\hline Ela & 15.32 & 16.98 & $16.15 \mathrm{a}$ & 0.68 & 0.45 & 0.57 a-e & 2.72 & 2.84 & $2.78 \mathrm{j}$ \\
\hline Hat-1 & 11.78 & 14.67 & $13.22 \mathrm{a}-\mathrm{d}$ & 0.56 & 0.73 & $0.65 \mathrm{a}-\mathrm{d}$ & 2.87 & 2.84 & $2.85 \mathrm{~g}-\mathrm{j}$ \\
\hline Hat-6 & 10.11 & 10.66 & 10.38 b-g & 0.45 & 0.22 & 0.34 b-e & 3.14 & 3.17 & $3.16 \mathrm{~b}-\mathrm{g}$ \\
\hline Hat-12 & 10.41 & 12.23 & 11.32 b-g & 0.35 & 0.53 & 0.44 b-e & 3.11 & 3.02 & $3.07 \mathrm{~d}-\mathrm{j}$ \\
\hline Hat-17 & 10.78 & 11.09 & $10.93 \mathrm{~b}-\mathrm{g}$ & 0.33 & 0.10 & 0.22 cde & 3.04 & 3.10 & $3.07 \mathrm{~d}-\mathrm{j}$ \\
\hline Hat-19 & 9.99 & 9.76 & $9.88 \mathrm{~b}-\mathrm{g}$ & 0.57 & 0.22 & $0.40 \mathrm{~b}-\mathrm{e}$ & 2.94 & 2.95 & $2.95 \mathrm{e}-\mathrm{j}$ \\
\hline Hat-15 & 10.65 & 14.04 & 12.35 a-f & 0.80 & 0.67 & $0.73 a b c$ & 2.79 & 2.86 & 2.83 hij \\
\hline Hat-18 & 10.10 & 11.12 & $10.61 \mathrm{~b}-\mathrm{g}$ & 0.90 & 0.30 & 0.60 a-e & 2.71 & 2.88 & $2.80 \mathrm{i}$ \\
\hline Coloratus & 7.11 & 8.56 & $7.83 \mathrm{fg}$ & 0.32 & 0.55 & $0.44 \mathrm{~b}-\mathrm{e}$ & 3.44 & 3.49 & $3.47 \mathrm{a}$ \\
\hline Albus & 6.87 & 10.03 & $8.45 \mathrm{~d}-\mathrm{g}$ & 0.79 & 0.65 & $0.72 a b c$ & 3.25 & 3.26 & $3.26 \mathrm{a}-\mathrm{d}$ \\
\hline 452 & 8.78 & 12.78 & $10.78 \mathrm{~b}-\mathrm{g}$ & 1.11 & 0.55 & $0.83 a b$ & 3.35 & 3.11 & 3.23 a-e \\
\hline $\begin{array}{l}\text { Leucotetragon } \\
\text { us }\end{array}$ & 6.00 & 10.09 & 8.04 efg & 0.00 & 0.11 & $0.06 \mathrm{e}$ & 3.50 & 3.30 & $3.40 a b$ \\
\hline Biflorus & 7.22 & 11.34 & $9.28 \mathrm{c}-\mathrm{g}$ & 0.78 & 0.54 & $0.66 \mathrm{a}-\mathrm{d}$ & 3.45 & 3.30 & $3.38 a b c$ \\
\hline İptaş & 7.67 & 12.10 & $9.88 \mathrm{~b}-\mathrm{g}$ & 0.44 & 0.43 & 0.44 b-e & 2.73 & 2.93 & 2.83 hıj \\
\hline Azureus & 6.22 & 8.10 & $7.16 \mathrm{~g}$ & 0.44 & 0.20 & $0.32 b-e$ & 3.19 & 3.10 & $3.14 \mathrm{~b}-\mathrm{g}$ \\
\hline 481 & 6.22 & 8.46 & $7.34 \mathrm{~g}$ & 0.55 & 0.53 & 0.54 a-e & 3.08 & 3.13 & $3.11 b-h$ \\
\hline Eren & 11.33 & 15.57 & $13.45 \mathrm{abc}$ & 0.22 & 0.31 & 0.27 b-e & 3.50 & 3.40 & $3.45 \mathrm{a}$ \\
\hline 553 & 9.45 & 13.89 & $11.67 \mathrm{a}-\mathrm{g}$ & 0.33 & 0.22 & $0.28 \mathrm{~b}-\mathrm{e}$ & 3.30 & 3.23 & $3.27 \mathrm{a}-\mathrm{d}$ \\
\hline Ortalama & $9.62 \mathrm{~b}$ & $12.14 \mathrm{a}$ & 10.88 & 0.50 & 0.43 & 0.47 & $3.08 \mathrm{~b}$ & $3.09 a$ & 3.09 \\
\hline
\end{tabular}

*Aynı harfle gösterilen ortalamalar $\mathrm{P} \leq 0.05$ hata sınırları içerisinde $\mathrm{SAS}$ istatistik analizine göre birbirinden istatistiki olarak farksızdır. 
Mürdümük bitkisinde biyolojik verim özelliğini inceleyen birçok araştırıcı tespit edilmiştir. Örneğin; Bayram ve ark. (2004) Bursa ekolojik koşullarında 289.23-689.37 kg/da, Karadağ ve ark. (2004) Tokat ekolojik koşullarında 456.6-685.8 $\mathrm{kg} / \mathrm{da}$, Bucak (2009) Şanlıurfa ekolojik koşullarında $330.24-413.89 \mathrm{~kg} / \mathrm{da}$ arasında değiştiğini rapor etmiştir. Elde edilen biyolojik verim sonuçları, yukarıdaki araştırıcıların bulgularından daha düşük olduğu saptanmıştır.

Bunun nedeni, denemenin yazlık olarak kurulmasından dolayı vejetasyon süresinin kısa olması ve denemenin yürütüldüğü vejetasyon dönemi içerisinde düşen toplam yağışların az olmasından kaynaklanmış olabilir.

Mürdümük genotiplerine ait iki yıllık tane verimleri incelendiğinde, yıllar arasındaki fark \% 1 düzeyide önemli derece de etkilerken, genotipler ve genotip $x$ yıl interaksiyonu arasındaki fark \% 5 düzeyinde önemli bulunmuştur (Tablo1). İki yıllık ortalama tane verimi sonuçlarına göre, en yüksek verim $117.47 \mathrm{~kg} / \mathrm{da}$ ile Hat -17 genotipten elde edilirken, bunu 508, 520, 531, 528, Coloratus, Albus, Leucotetragonus ve Biflorus genotiplerinin dışındaki istatistiki olarak aynı grupta yer alan diğer tüm genotipler izlemiştir. En düşük tane verimi $75.10 \mathrm{~kg} / \mathrm{da}$ ile 528 nolu genotipten elde edilmiştir. Tane verimi değerleri 2014 yılında genotiplerin ortalaması olarak 75.39 kg/da iken, 2015 yılında $117.52 \mathrm{~kg} /$ da olmuştur (Tablo 1).

Farklı ekolojilerde ve farklı zamanlarda yürütülen araştırmalarda mürdümükte tohum veriminin $67.3 \mathrm{~kg} / \mathrm{da}$ ile $352.0 \mathrm{~kg} / \mathrm{da}$ arasında değiştiği birçok araştırıcı tarafından bildirilmektedir (Sabancı ve Özpınar, (2000); Milczak ve ark. (2001); Bayram ve ark. (2004); Gül ve ark. (2004); Bucak (2009); Kökten ve Bakoğlu (2011); Karadağ ve ark. (2012); Zahra ve ark. (2013).

Farklı bölgelerde ve ekolojilerde yürütülen mürdümük ve benzer bitkilerin tane verimleri incelendiğinde; Bayram ve ark. (2004) Bursa ekolojik koşullarında 67.30-202.88 kg/da, Karadağ ve ark. (2004) Tokat ekolojik koşullarında 102.9$168.1 \mathrm{~kg} / \mathrm{da}$, Bucak (2009) Şanlıurfa ekolojik koşullarında 95.60-174.68 kg da, Seydoşoğlu ve ark. (2015) Diyarakır ekolojik koşullarında 181.00-269.83 $\mathrm{kg} / \mathrm{da}$, Kökten ve ark. (2019) Bingöl koşularında 50.3-82.6 kg da arasında değiştiğini bildirmişlerdir. Elde edilen tohum verimi değerleri ile literatürdeki sonuçlardan daha düşük bulunmuştur. Bunun nedeni olarak, araştırmada kullanılan genotiplerin, ekolojik faktörlerden, ekim zamanlarının farklı olmasından kaynaklandığı söylenebilir.

Mürdümük genotiplerine ait iki yıllık dolu bakla sayısı verileri incelendiğinde araştırma konusu olan genotiplerin dolu bakla sayısı ortalamaları, yıllar ve genotipler arasındaki farklılık \%1 düzeyinde önemli bulunurken genotip $x$ yıl interaksiyonu ortalamaları arasındaki farklılık istatistiksel olarak önemsiz bulunmuştur (Tablo 2). Birleştirilmiş yılların ortalama bitkide dolu bakla sayısı en yüksek 16.15 adet/bitki ile Ela genotipinden elde edilirken, bunu istatistiksel olarak aynı grupta yer alan 508, 528, Eren, 504, Hat-1, Elazığ popülasyon, 520, Hat-15, 522, 553 nolu genotipler izlemiştir. En düşük bitkide dolu bakla sayısı 7.16 adet/bitki ile Azureus genotipinden elde edilmiştir.

Bitkide ortalama dolu bakla sayısı 2014 yılında 9.62 adet/bitki elde edilirken, 2015 yılında ise 12.14 adet/bitki olduğu saptanmıştır. Elde edilen bitkide dolu bakla sayısı, farklı ekolojilerde yapılan çalışmaların bitkide dolu bakla sayısı arasında farklılıklar olduğu tespit edilmiştir (Kumar ve Dubey, 2003; Tadesse ve Bekele, 2003; Bucak, 2009; Seydoşoğlu ve ark. 2015). Bu farklılığın nedeni olarak, bitkinin ekim zamanı (yazlık-kışık), ekim sıklığı, toprak yapısı ve özellikle ekolojik koşullardan olduğu söylenebilir.

Mürdümük genotiplerine ait iki yıllık boş bakla sayısı verileri incelendiğinde, genotipler arasındaki farklılık \%5 düzeyinde önemli bulunurken yıllar ve genotip $x$ yıl interaksiyonu ortalamaları arasındaki farklılık istatistiksel olarak önemsiz bulunmuştur (Tablo 2). 2014-2015 yılı ortalama boş bakla sayısı sonuçlarına göre, en yüksek boş bakla sayısı 1 adet/bitki ile 504 nolu genotipten elde edilirken, bunu istatistiksel olarak aynı grupta yer alan 452, Hat-15, Albus, Biflorus, 508, 528, Hat-1, 563, Ela, 481ve 531 nolu genotipler izlemiştir. En düşük boş bakla sayısı 0.06 adet/bitki ile Leucotetragonus genotipinden elde edilmiştir. Boş bakla sayısı değerleri 2014 yılında genotiplerin ortalaması olarak 0.50 adet/bitki iken, 2015 yılında 0.43 adet/bitki olmuştur (Tablo 2).

Bu çalışmadan elde edilen 0.06-1 adet bitkideki boş bakla sayısı Gedik (2007)'in tespit ettiği 12-18 adet boş bakla sayısından oldukça düşüktür. Bu değerler arasındaki farklılık çalışmada kullanılan genotiplere ve bakla dolumu sırasındaki sıcaklık ve yağışa bağlı olarak değişkenlik gösterebilir.

Araştırmada incelenen mürdümük genotiplerine ait iki yıllık ortalama bakla boyu verileri incelendiğinde, genotipler arasındaki farklılık \%1 düzeyinde önemli bulunurken yıllar ve genotip x yıl interaksiyonu ortalamaları arasındaki farklılık istatistiksel olarak önemsiz bulunmuştur (Tablo 2). ìki yıllık ortalama bakla boyu sonuçlarına göre, en yüksek bakla boyu $3.47 \mathrm{~cm}$ ile Coloratus ve 3.45 ile Eren genotiplerinden elde edilirken, bunu istatistiksel olarak aynı grupta yer alan, Leucotetrogonus, Biflorus, 553, Albus, 452, Karadağ ve 528 nolu genotipler izlemiştir. En düşük bakla $2.78 \mathrm{~cm}$ ile Ela genotipinden elde edilmiştir. Bakla 
boyu değerleri 2014 yılında genotiplerin ortalaması olarak 3.08 cm iken, 2015 yılında 3.09 olmuştur.

Bakla boyu ile ilgili özellik incelendiğinde; Kendir (1999) Ankara koşullarında 30.00-35.67 cm, Bucak (2009) Şanlıurfa ekolojik koşullarında 23.68-27.58 $\mathrm{cm}$ olarak rapor etmişlerdir. Elde edilen bulgular, literatürdeki sonuçlardan daha düşük olduğu tespit edilmiştir. bunun nedeni olarak, kullanılan materyallerin, ekolojik faktörlerin ve toprak yapısından kaynaklandığı söylenebilir.

Tablo 3: Bakla genişliği, bitkide tane sayısı ve bitkide tane ağırlığına ilişkin ortalama değerler ve oluşan gruplar

\begin{tabular}{|c|c|c|c|c|c|c|c|c|c|}
\hline \multirow{2}{*}{ Genotipler } & \multicolumn{3}{|c|}{ Bakla Genişliği (cm) } & \multicolumn{3}{|c|}{ Bitkide Tane Sayısı (adet) } & \multicolumn{3}{|c|}{ Bitkide Tane Ağırlığı (g) } \\
\hline & 2014 & 2015 & Ortalama & 2014 & 2015 & Ortalama & 2014 & 2015 & Ortalama \\
\hline 508 & 0.79 & 0.87 & $0.83 \mathrm{j}$ & 30.32 & 36.25 & $33.29 \mathrm{bcd}$ & 2.72 & 3.64 & 3.18 a-e \\
\hline 520 & 0.93 & 1.04 & 0.98 e-I & 28.12 & 38.65 & $33.39 \mathrm{bcd}$ & 2.48 & 3.98 & 3.23 a-e \\
\hline 563 & 0.89 & 0.89 & j & 24.23 & 35.19 & $29.71 \mathrm{~b}-\mathrm{g}$ & 2.99 & 4.57 & $3.78 \mathrm{abc}$ \\
\hline 531 & 0.89 & 0.97 & $0.93 \mathrm{~g}-\mathrm{j}$ & 24.54 & 33.65 & $29.10 \mathrm{~b}-\mathrm{g}$ & 2.11 & 3.06 & 2.59 cde \\
\hline 528 & 0.94 & 0.93 & $0.93 \mathrm{~g}-\mathrm{j}$ & 26.54 & 39.84 & $33.19 \mathrm{bcd}$ & 2.54 & 4.21 & 3.37 a-e \\
\hline 522 & 0.89 & 0.94 & 0.92 hij & 26.67 & 34.13 & 30.40 b-g & 2.45 & 3.12 & 2.78 b-e \\
\hline 504 & 0.87 & 0.92 & j & 27.43 & 43.48 & $35.46 a b c$ & 2.33 & 5.21 & $3.77 \mathrm{abc}$ \\
\hline Karadağ & 0.94 & 0.98 & $0.96 \mathrm{f}-\mathrm{I}$ & 19.43 & 29.58 & 24.50 b-I & 2.23 & 3.23 & 2.73 cde \\
\hline $\begin{array}{c}\text { Elazı̆̆ } \\
\text { Popülasyon }\end{array}$ & 0.88 & 1.00 & $0.94 \mathrm{f}-\mathrm{j}$ & 30.22 & 41.68 & $35.95 a b$ & 2.85 & 4.50 & 3.68 a-d \\
\hline $\begin{array}{c}\text { Mardin } \\
\text { Popülasyon }\end{array}$ & 0.91 & 0.97 & $0.94 \mathrm{f}-\mathrm{j}$ & 16.33 & 37.15 & 26.74 b-ו & 1.81 & 4.69 & 3.25 a-e \\
\hline Adıyaman & 0.90 & 0.96 & $0.93 \mathrm{gj}$ & 19.89 & 36.87 & $28.38 b-h$ & 1.95 & 4.72 & 3.33 a-e \\
\hline Gürbüz-2001 & 0.90 & 0.98 & $0.94 \mathrm{f}-\mathrm{j}$ & 20.88 & 27.62 & 24.25 c-I & 2.43 & 3.64 & 3.04 a-e \\
\hline İfls-491 & 0.94 & 1.03 & ו-e 0.99 & 18.11 & 23.13 & 20.62 e- & 2.02 & 2.28 & $2.15 \mathrm{e}$ \\
\hline Ela & 0.78 & 0.88 & $0.83 \mathrm{j}$ & 40.89 & 49.28 & $45.08 \mathrm{a}$ & 3.08 & 4.71 & $3.89 \mathrm{abc}$ \\
\hline Hat-1 & 0.97 & 0.96 & ו ו- 0.97 & 24.32 & 38.40 & $31.36 b-f$ & 3.07 & 5.33 & $4.20 \mathrm{ab}$ \\
\hline Hat-6 & 0.88 & 0.94 & 0.91 hij & 25.56 & 29.57 & 27.57 b-ו & 2.53 & 2.74 & 2.64 cde \\
\hline Hat-12 & 1.00 & 0.97 & ו-e e.99 & 22.11 & 28.93 & ו ו-b.52 & 2.84 & 3.60 & 3.22 a-e \\
\hline Hat-17 & 0.88 & 0.93 & j & 21.11 & 32.28 & I- ו-b.70 & 2.59 & 3.77 & 3.18 a-e \\
\hline Hat-19 & 1.06 & 1.10 & $1.05 c-f$ & 18.66 & 27.99 & ו-e 21.48 & 2.11 & 3.55 & 2.60 cde \\
\hline Hat-15 & 0.98 & 1.02 & 1.00 e- & 19.23 & 28.18 & $23.71 \mathrm{~d}-$ I & 2.72 & 3.89 & 3.30 a-e \\
\hline Hat-18 & 1.04 & 1.02 & $1.03 \mathrm{~d}-\mathrm{g}$ & 17.23 & 27.33 & $22.28 \mathrm{~d}-1$ & 2.33 & 3.71 & 3.02 a-e \\
\hline Coloratus & 1.22 & 1.18 & $1.20 \mathrm{ab}$ & 14.33 & 20.22 & 17.28 hı & 1.94 & 2.71 & $2.32 \mathrm{de}$ \\
\hline Albus & 1.20 & 1.16 & $1.18 a b$ & 15.11 & 23.67 & $19.39 \mathrm{ghı}$ & 1.95 & 3.91 & 2.93 a-e \\
\hline 452 & 1.06 & 1.03 & $1.05 c-f$ & 18.00 & 35.43 & 26.72 b-ו & 2.16 & 4.51 & 3.33 a-e \\
\hline $\begin{array}{c}\text { Leucotetragonu } \\
\mathrm{s}\end{array}$ & 1.17 & 1.12 & $1.14 \mathrm{abc}$ & 12.00 & 25.88 & $18.94 \mathrm{ghı}$ & 1.67 & 3.78 & 2.72 cde \\
\hline Biflorus & 1.23 & 1.23 & $1.23 \mathrm{a}$ & 12.55 & 27.25 & $19.90 \mathrm{f}-\mathrm{I}$ & 1.78 & 4.44 & 3.11 a-e \\
\hline İptaş & 1.00 & 1.03 & 1.02 e-h & 15.55 & 32.74 & 24.15 c-I & 1.74 & 4.46 & 3.10 a-e \\
\hline Azureus & 1.23 & 1.20 & $1.22 \mathrm{ab}$ & 12.00 & 22.11 & 17.06 hı & 1.59 & 2.47 & $2.03 \mathrm{e}$ \\
\hline 481 & 0.98 & 0.97 & ו-e.97 & 11.78 & 21.69 & I6.73। & 1.37 & 2.84 & $2.11 \mathrm{e}$ \\
\hline Eren & 1.15 & 1.10 & $1.13 \mathrm{bcd}$ & 23.55 & 39.93 & 31.74 b-e & 3.06 & 5.39 & $4.23 \mathrm{a}$ \\
\hline 553 & 1.05 & 1.10 & $1.08 \mathrm{cde}$ & 20.67 & 38.53 & $29.60 \mathrm{~b}-\mathrm{g}$ & 2.64 & 4.96 & $3.80 \mathrm{abc}$ \\
\hline Ortalama & $0.99 \mathrm{~b}$ & $1.01 \mathrm{a}$ & 1 & $21.21 b$ & $32.47 \mathrm{a}$ & 26.78 & $2.33 \mathrm{~b}$ & $3.92 \mathrm{a}$ & 3.12 \\
\hline
\end{tabular}

*Aynı harfle gösterilen ortalamalar $\mathrm{P} \leq 0.05$ hata sınırları içerisinde $\mathrm{SAS}$ istatistik analizine göre birbirinden istatistiki olarak farksızdır. 
Bakla genişliğine ait veriler incelendiğinde araştırma konusu olan genotiplerin bakla genişliği ortalamaları arasındaki fark, yıllar arasında \%5, genotipler arasında \%1 düzeyinde önemli bulunurken genotip $\mathrm{x}$ yıl interaksiyonu ortalamaları arasındaki fark ise istatistiksel olarak önemsiz bulunmuştur. İki yıllık ortalama bakla genişliği sonuçlarına göre, en yüksek bakla genişliği $1.23 \mathrm{~cm}$ ile Biflorus genotipten elde edilirken, bunu istatistiksel olarak aynı grupta yer alan Azureus, Coloratus, Albus ve Leucotetrogonus genotipleri izlemiştir. En düşük bakla genişliği $0,83 \mathrm{~cm}$ ile 508 ve Ela genotipinden elde edilmiştir. Bakla genişliği değerleri 2014 yılında genotiplerin ortalaması olarak $0.99 \mathrm{~cm}$ iken, 2015 yılında $1.01 \mathrm{~cm}$ olmuştur (Tablo 3).

Mürdümük genotiplerinin tane sayısı verileri incelendiğinde genotiplerin bitkide tane sayısı ortalamaları arasındaki fark yıllar ve genotipler arasında \%1 düzeyinde önemli bulunurken genotip $x$ yıl interaksiyonu ortalamaları arasındaki farklılık ise istatistiksel olarak önemsiz bulunmuştur. İki yıllık ortalama bitkide tane sayısı sonuçlarına göre, en yüksek bitkide tane sayısı 45 adet ile Ela genotipten elde edilirken, bunu istatistiksel olarak aynı grupta yer alan Elazığ popülasyon ve 504 genotipleri izlemiştir. En düşük bitkide tane sayısı 16,73 adet ile 481 genotipinden elde edilmiştir. Ortalama bitkide tane sayısı değerleri 2014 yılında 21,21 adet iken, 2015 yılında 32,47 adet olmuştur (Tablo 3). Kumar ve Dubey (2003) yaptıkları araştırmada bitki başına tane sayısının 54-208.3 adet arasında değiştiğini saptamışlardır. Bayram ve ark. (2004), başka bir araştırmada bitkide tane sayısının 100.17-202.73 adet olarak saptamışlardır. Araştırmada elde edilen 26,78 adet ortalama bitki başına tohum sayısı değeri, bu araştırmacıların elde ettiği değerlerden daha düşüktür. Elde edilen değerin diğer araştırmacıların elde ettiği değerlerden farklı olmasının sebebi; denemelerin yürütüldüğü yerlerde bitkinin yetişme dönemi boyunca düşen toplam yağışlar, ortalama sıcaklık ve denemelerde kullanılan genotiplerin farklılığından kaynaklandığı söylenebilir.

Incelenen genotiplere ait iki yıllık ortalama bitkide tane ağırlığı verileri incelendiğinde, yıllar ve genotipler arasındaki farklılık \%1 düzeyinde önemli bulunurken genotip $\mathrm{x}$ yıl interaksiyonu ortalamaları arasındaki farklılık istatistiksel olarak önemsiz bulunmuştur. İki yıllık ortalama bitkide tane ağırlığı sonuçlarına göre, en yüksek bitkide tane ağırlığı 4.23 g ile Eren genotipten elde edilirken, bunu 531, 522, Karadağ, iffs-491, Hat-6, Hat-19, Coloratus, Leucoteragonus, 481 ve Azureus genotiplerinin dışındaki istatistiki olarak aynı grupta yer alan diğer tüm genotipler izlemiştir. En düşük bitkide tane ağırlığı 2.03 g ile Azureus, $2.11 \mathrm{~g}$ ile 481 ve $2.15 \mathrm{~g}$ ile ifls-491 nolu genotiplerden elde edilmiştir. Ortalama bitkide tane ağırlığı değerleri 2014 yılında 2.33 g iken,
2015 yılında $3.92 \mathrm{~g}$ olmuştur (Tablo 3). Kumar ve Dubey (2003), bitki başına tohum veriminin 2.06$23.67 \mathrm{~g}$ arasında değiştiğini saptamışlardır. Yapılan araştırmada $3.12 \mathrm{~g}$ olarak bulunan ortalama bitki başına tohum verimi değeri bu değerlerin arsında yer almaktadır. Araştırmada elde edilen 3.12 g ortalama bitki başına tohum verimi değeri, Bayram ve ark. (2004)'nın 10.16-26.31 g olarak saptadıkları ve Tadesse ve Bekele (2003)'nin 65.9-107.3 g, Bucak (2009 )'ın 3.22-5.46 g olarak saptamış oldukları değerlerden daha düşük bir değerdir.

\section{Sonuç ve Öneriler}

Yapılan çalışmaya göre, Elazığ ili iklim ve toprak koşullarında tarla tarımında özellikle tarlayı nadasa bırakmak yerine tek yıllık baklagil yem bitkisi olan mürdümük yetiştiriciliğinin yapılması iyi sonuçlar vereceği belirlenmiştir. $\mathrm{Bu}$ anlamda mürdümük bitkisi; hem baklagil bitkisi olmasından dolayı kendisinden sonra gelecek ürüne iyi bir toprak yapısı bırakacak, hem de tohum amacıyla ekilmek suretiyle yöre çiftçisine ek gelir sağlayacaktır. Tüm bu sonuçlar göz önünde bulundurulduğunda, Hat-17 genotipi verim açısından diğer genotiplere göre üstün verim potansiyeline sahip olduğu tespit edilmiştir.

\section{Teşekkür}

Bu çalışmanın 2014 yılı verileri Bingöl Üniversitesi Bilimsel Araştırma Projeleri Birimi tarafından desteklenen Selim Özdemir'in yüksek lisans tezinden alınmıştır (Proje No: BAP-82-1952014).

\section{Kaynaklar}

Anonim.2016. Elazığ Meteoroloji 13. Bölge Müdürlüğü iklim verileri.

Aydeniz, A. Brohi, AR. 1991. Gübreler Ve Gübreleme. Ç.Ü. Tokat Ziraat Fakültesi Yayın No: 10. Ders Kitabı No: 3, Tokat.

Bayram, G., Türk, M., Budaklı, E. ve Çelik, N. 2004 Bursa ekolojik koşullarında yetiştirilen yaygın mürdümük (Lathyrus sativus L.) hatlarının verim ve adaptasyonu üzerinde bir araştırma. Uludağ Üniversitesi Ziraat Fakültesi Dergisi, 18(2): 73-84.

Bucak, B., Baysal, i. 2001. Harran ovası koşullarında kışlık olarak yetiştirilen mürdümük (Lathyrus sativus L. ve L. cicera ) hatlarında tohum verimi ve bazı özelliklere etkisi üzerinde bir araştırma. Harran Üniversitesi Ziraat Fakültesi Dergisi. 5(3-4): 33-43.

Bucak, B. 2009. Harran ovasında kışlık olarak yetiştirilen mürdümük türlerine ait (Lathryus sativus L. ve Lathryus ciceria L.) 10 hattın bazı morfolojik ve agronomik özelliklerininin belirlenmesini üzerine bir araştırma. Harran 
Üniversitesi Ziraat Fakültesi Dergisi. 13(4): 5765.

Gedik, A. 2007. Bazı mürdümük ( lathyrus sativus I.) varyete, hat ve çeşitleri arasındaki morfolojik, tarımsal ve moleküler farklılıkların saptanması üzerine bir araştırma Çukurova Üniversitesi Fen Bilimleri Enstitisü yüksek lisans tezi sayfa:34.

Gül, D., Sümerli, M. ve Yılmaz, Y. 2004. Diyarbakır kosullarında bazı mürdümük (Lathyrus sativus L.) hatlarının verim ve verim unsurlarının belirlenmesi". Ankara Üniversitesi Ziraat Fakültesi Tarım Bilimleri Dergisi. 10(4): 416421.

Karadağ, Y., İptaş, S. ve Yavuz, M. 2004. Agronomic potential of grasspea (Lathyrus sativus L.) under rainfed condition in semi-arid regions of Turkey. Asian Journal of Plant Sciences. 3(2): 151-155.

Karadağ, Y., Özkurt, M., Akbay, S. ve Kır, H. 2012. Tokat-Kazova ekolojik koşullarında bazı mürdümük (Lathyrus sativus L.) hatlarının verim ve verim özelliklerinin belirlenmesi. Journal of Agricultural Sciences. 5(2): 11-13.

Kendir, H. 1999. Adi mürdümük (Lathyrus sativus L.) hatlarının tohum verimi ve verim komponentleri. Tarım Bilimleri Dergisi. 5(3): 73-81.

Kökten, K. ve Bakoğlu, A. 2011. Elazığ koşullarında mürdümük (Lathyrus sativus L.)'te farklı sıra arasının tohum verimi ve verim öğeleri üzerine etkisi. Bingöl Üniversitesi Fen Bilimleri Dergisi. 1(1): 37-42.

Kökten, K., Kaplan, M., Seydoşoğlu, S., Tutar, H., Özdemir, S. 2019. Determination of Seed Yield, Straw Yield and Quality of Some Bitter Vetch (Vicia ervilia L. Willd) Genotypes in Bingol Ecological Conditions, Ege Univ. Ziraat Fak. Derg., 56 (1):27-33.

Kumar, 1997. Utilization of Lathyrus. Lathyrus Genetic Resources Network. 8-10 December. New Delhi/India, 57-59.

Kumar, S. ve Dubey, A.K. 2003. Genetic diveristy among induced mutanst of grasspea (Lathyrus sativus L.). Lathyrus Lathyrism Newsletter. 3: 15-17.
Milczak, M., Pedzinski, M., Mnichowska, H., Szwedurbas, K. ve Rybinski, W. 2001. Creative breeding of grasspea (Lathyrus sativus L.) in Poland. Lathyrus Lathyrism Newsletter. 2: 8588.

Sabancı, CO. ve Özpınar, H. 2000. Bazı yem bitkilerinin menemen koşullarına adaptasyonları üzerine araştırmalar. Anadolu Journal of Agricultural Sciences. 10 (1): 43-51.

SAS Inst. 1999. SAS User's Guide. Statistic. Statistical Analysis Systems Institute Inc. Cary. NC.

Seydoşoğlu, S., Saruhan, V., Kökten, K. ve Karadağ, Y. 2015. Diyarbakır Ekolojik Koşullarında Bazı Mürdümük (Lathyrus sativus L.) Genotiplerinin Verim ve Verim Unsurlarının Belirlenmesi". Gaziosmanpaşa Üniversitesi Ziraat Fakültesi Dergisi. 32 (3): 98-109.

Seydoşoğlu, S., 2018. Bazı doğal mera alanlarının bitki örtüsü özellikleri, mera durumu ve sağığının belirlenmesi. Turkish Journal of Forestry, 19(4): 368-373.

Seydoşoğlu, S., Kökten, K. 2019. Batman Mera Vejetasyonlarının Bazı Özellikleri, Harran Tarım ve Gıda Bilimleri Dergisi, 23(1): 27-33.

Seydoşoğlu, S., Çaçan, E., Sevilmiş, U. 2019. Determination of botanical composition yield and pasture quality rating of infertile pastures in Kozluk district of Batman province of Turkey. Fresenius Environmental Bulletin Volume 28 (4A) p:3388-3394.

Tadesse, W. ve Bekele, E. 2003. Variation and association of morphological and biochemical caharacteristics in grasspea (Lathyrus sativus L.). Euphytica. 130: 315-324.

Tekele-Haimanot, R., Kidane, Y., Wuhib, E., Kalissa, A., Alemu, T., Zein, ZA. ve Spencer, PS. 1990. Lathyrism in rural Northwestern Ethiopia: a highly prevalent neurotoxic disorder. Int. J. Epidemiol. 19: 664-672.

Zahra, A., Ashraf, JA., Shahram, N., Bahman, Y. ve Karim, K. 2013. Effects of sowing season on herbage and seed production of grasspea under rainfed condition of Khoramabad. Iran. Legume Research. 36(6): 535-544. 